\title{
Fluorescent Antibody Techniques for the Diagnosis of Enteric Infections
}

\author{
By
}

\author{
Gordon C. Brown* \\ With 5 Figures
}

The very excellent papers which have preceded this presentation have described several methods of identification of viruses following isolation and have emphasized the necessity of accurate methods of isolation and identification. Dr. Herdis von Magnus in particular has mentioned several methods of diagnosis by the technique of measuring serum antibodies in acute and convalescent sera which are used particularly as diagnostic tools when virus isolation is impossible. In addition, serum antibody studies have had application in research such as in studying the response to vaccination.

I would like to describe a technique which is different from any of those mentioned by Dr. von Magnus; namely, the fluorescent antibody technique which we, in our laboratory, are particularly interested in at the present time. We are still in the process of comparing our results obtained by this technique with results obtained by other techniques to be absolutely certain that we may rely upon them entirely and by themselves. This seems highly likely at the present time. There are many advantages to the fluorescent antibody technique, one of which is that is serves both for isolation and identification and for an evaluation of serum antibodies. A second advantage is that it is a rapid procedure enabling one to obtain final results in a few hours rather than after several days as is the case with certain other procedures.

Isolation and Identification of Virus. For the isolation and identification of enterovirus, we use the direct method of fluorescent microscopy. For instance, a stool specimen suspected of harboring the agent is processed in the routine manner and inoculated into several tissue culture tubes in which small coverslips have been placed so that the cells grow on

* Professor, Department of Epidemiology, School of Public Health, University of Michigan, Ann Arbor, Michigan. 

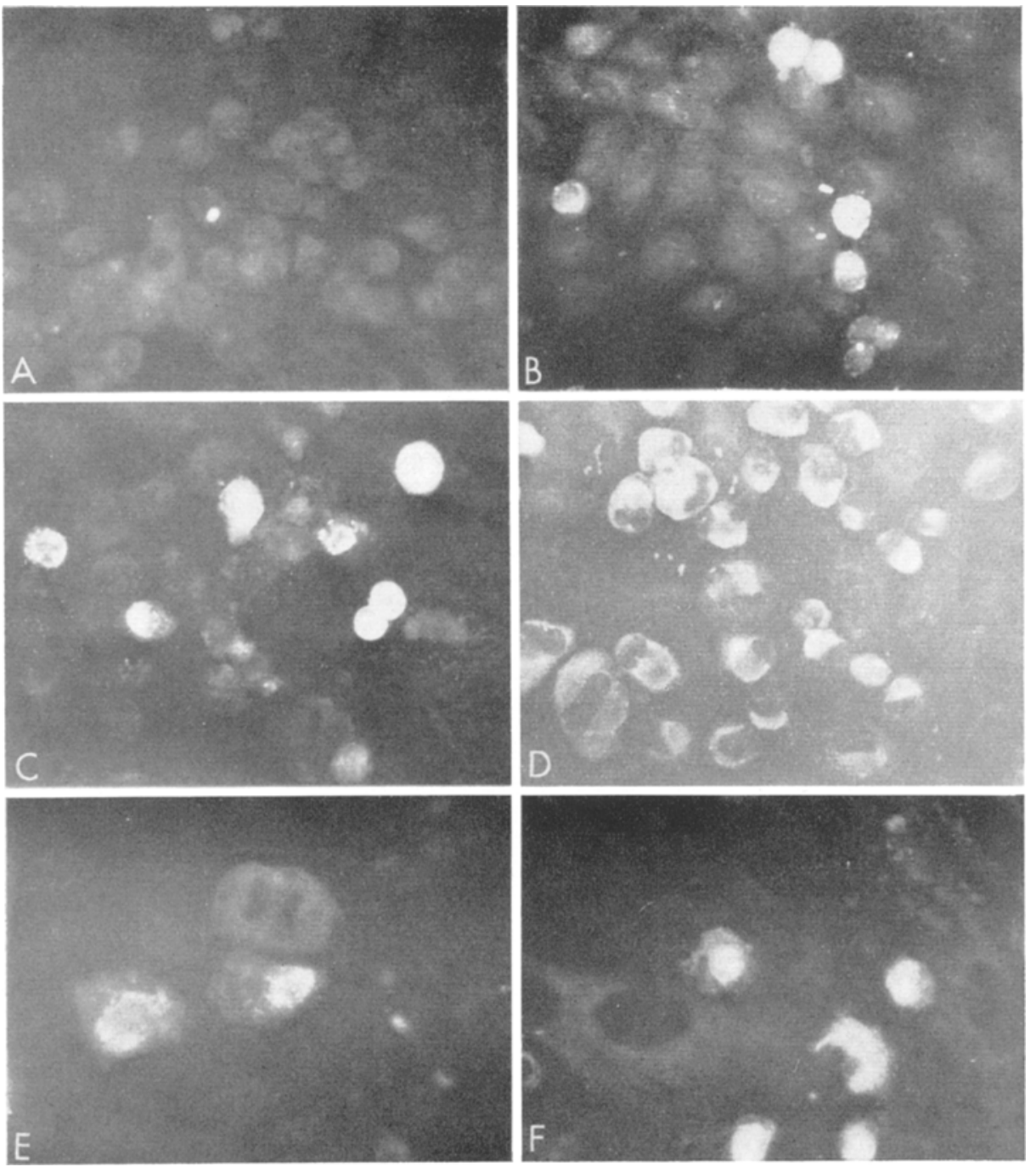

Fig. 1. A. Control - HeLa cells infected with poliovirus type II, stained by the direct method with fluorescein labeled anti type III antibody $(\times 400)$.

B. HeLa cells infected with poliovirus type I, stained by the direct method with rhodamine labeled anti type I antibody $(\times 400)$.

C. Hela cells infected with poliovirus type II, stained by the direct method with fluorescein labeled anti type II antibody $(\times 400)$.

D. HeLa cells infected with poliovirus type III, stained by the indirect technique. T'he intermediate (patient's) serum was diluted $1: 32$, and the final serum was fluorescein labeled anti-human gamma globulin $(\times 400)$.

E. HeLa cells infected with Coxsackie B 1 virus, stained by the indirect technique. The intermediate (patient's) serum was diluted $1: 16$, and the final serum was fluorescein labeled anti-human gamma globulin $(\times 400)$.

F. Monkey kidney cells infected with ECHO 9 virus, stained by the indirect technique. The intermediate (patient's) serum was diluted $1: 32$, and the final serum was fluorescein labeled anti-human gamma globulin $(\times 400)$, 
the glass of the coverslips. The tubes containing the stool specimen are incubated at $37^{\circ} \mathrm{C}$ for approximately 24 hours at which time the coverslips are removed and placed in acetone for fixation. Following washing,

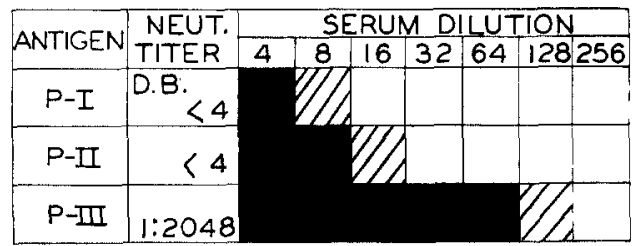

\begin{tabular}{|c|c|c|c|c|}
\hline & NEUT, & SERUM DI & LUTIC & $\overline{O N}$ \\
\hline ANIIGEN & TITER & \begin{tabular}{l|l}
16 & 32
\end{tabular} & 64 & 128256 \\
\hline$P-I$ & $\begin{array}{l}A, B \\
1: 2048\end{array}$ & & & \\
\hline P-II & $<4$ & & & \\
\hline P-III & $<4$ & & & \\
\hline
\end{tabular}

Fig. 2. Identification of polio antibodies in human serum by indirect fluorescence microscopy (labeled goat anti-human gamma gfobulin). Sera from convalescent cases of virus confirmed poliomyelitis. these are mounted on regular glass slides and stained with various hyperimmune sera which have been labeled with fluorescein isothiocyanate. Fractionation of the serum on a DEAE column prior to use is of great benefit in eliminating nonspecific reactions. If coverslip cultures are not available, infected cells may be scraped off the glass, fixed to slides, and stained as above. Identification of the virus which was present in the original stool specimen is obtained by determining which immunologic type of antiserum gives specific fluorescence with the cells and in all cases this diagnosis may be obtained within 24 hours even thougb the

\begin{tabular}{ll|r|r}
\hline \multicolumn{2}{c|}{ Virus } & Neut. & F. A. \\
\hline Polio & I & 64 & 16 \\
& & 256 & 16 \\
Polio II & 2048 & 32 \\
& & 64 & 8 \\
Polio III & 256 & 16 \\
& & 1024 & 16 \\
& & 256 & 16 \\
Cox. & 1024 & 32 \\
& B-1 & 2048 & 64 \\
& B-2 & 256 & 32 \\
& B-2 & 64 & 16 \\
& B-3 & 256 & 32 \\
& B-3 & 128 & 32 \\
& B-4. & 64 & 16 \\
& B-4 & 128 & 32 \\
B-5 & 512 & 16 \\
ECHO & -9 & 128 & 32 \\
& -9 & 256 & 64 \\
& & 1021 & 32
\end{tabular}

Fig. 3. Comparison of virus neutralizing and fluorescent antibody (indirect) titers of human sera. cells have not shown any cytopathogenic effect. Several examples of this technique are shown in Fig. 1. A represents a control in which HeLa cells infected with poliovirus type II do not stain with antibody against type III poliovirus. $\mathrm{B}$ is an example of a type specific reaction in which HeLa cells infected with poliovirus type I are stained with labeled anti type I antibody. Cillustrates the fluorescence obtained when type II antibody is added to type II infected cells. This type of specific reaction is also obtained with Coxsackie and ECHO viruses when stained with appropriate type specific antisera. One additional possibility of this direct technique is that tissue obtained following autopsy may be sectioned and stained in the same manner. We have been successful in identifying ECHO and Coxsackie virus in tissue sections by this technique but to 
date the demonstration of poliomyelitis virus in tissue sections has not been possible.

Identification and Titration of Serum Antibodies. While the direct method of fluorescent microscopy has proved useful in identifying virus isolates, the indirect method of identification and titration of serum antibodies is particularly useful in that it is rapid, specific, and has one distinct advantage over other serologic methods in that it uses very small amounts of serum. For this technique the tissue cells are grown on coverslips and then deliberately infected with various enteroviruses. These cells may be prepared ahead

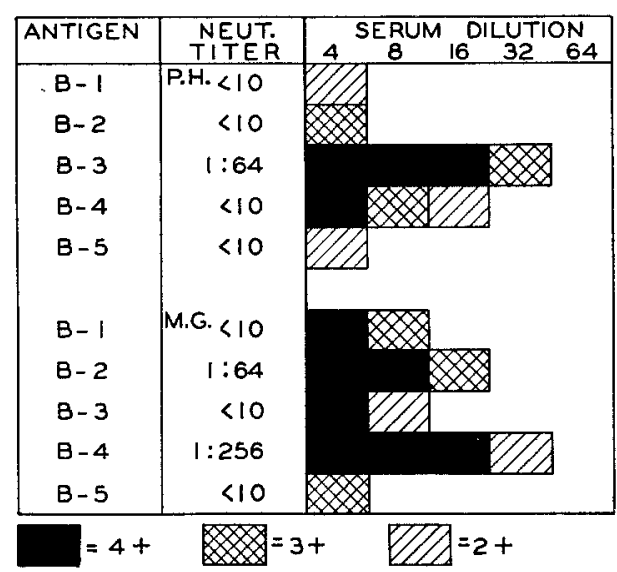

Fig. 4. Identification of Coxsackie antibodies in human serum by indirect immumofluorescence. of time and retained in the cold room until needed. A few drops of each dilution of an unknown serum is added to each coverslip and allowed to stand overnight at $4^{\circ} \mathrm{C}$. The next morning after removing the serum and washing with buffered saline, the slides are stained for one hour at $37^{\circ} \mathrm{C}$ with labeled antiserum prepared against the species of the intermediate (unknown) serum. The advantage of this technique is that only one conjugated serum, for instance a labeled antihuman serum, is necessary for the diagnosis of various kinds of antibodies in a given specimen. Furthermore, itis possible to obtain specific reactions following dilution of the unknown serum and even to titrate the antibodies. Part D in Fig. 1 illustrates a specific reaction obtained with a 1:32 dilution of a patient's serum which has been added to HeLa cells

\begin{tabular}{|c|r|r|r|r|r|}
\hline ANTIGEN & NEUT. & SERUM DILUTION \\
\hline TITER & 8 & 16 & 32 & 64 \\
\hline P-I & $\begin{array}{r}\text { S.M-I } \\
<4\end{array}$ & & & & \\
\hline P-II & $<4$ & & & & \\
\hline P-III & $<4$ & & & & \\
\hline
\end{tabular}

\begin{tabular}{|c|c|c|c|c|c|}
\hline ANTIGEN & NEUT. SERUM DILUTION \\
\hline TITER & 8 & 16 & 32 & 64 \\
\hline P-I & $\begin{array}{c}\text { S.M.-2 } \\
1: 64\end{array}$ & & & \\
\hline P-II & $1: 256$ & & & \\
\hline P-III & $1: 16$ & & & \\
\hline
\end{tabular}

Fig. 5. Identification of polio antibodies in human serum by indirect fluorescence microscopy (labeled goat anti-human gamma globulin).

S. M. -1 equals prevaccine specimen. S. M. -2 equals postraccine specimen. infected with poliovirus type III and then stained with an anti-human serum. $\mathbf{E}$ and $\mathbf{F}$ portray equally specific reactions which human sera containing antibodies against Coxsackie B 1 and ECHO9 viruses respectively. 
Fig. 2 illustrates graphically the results obtained with sera of patients who were convalescent from paralytic poliomyelitis. The solid black squares represent $4+$ reactions and it can be seen that in each case the specificity of the fluorescent antibody reaction agrees with the results obtained by neutralization tests on the same serum specimen. Fig. 3, however, shows that the actual titers obtained with FA technique are definitely lower than the neutralization titers. Fig. 4 shows the result;s obtained with human sera which were tested against five types of Coxsackie $B$ virus. These individuals were not ill and therefore the results illustrate that antibodies following subclinical infection may be demonstrated by this same technique. These results also illustrate the correlation of $\mathrm{FA}$ results with neutralization results, especially if one disregards the results obtained with the $1: 4$ dilution of serum which frequently presents a nonspecific reaction. A further application of this technique is seen in Fig. 5 which portrays both the neutralizing antibody titer as well as FA titer before and after immunization with inactivated poliomyelitis vaccine.

The application of this technique, therefore, would seem to represent a distinct advance in the identification of either enteroviruses or their antibodies and is a useful adjunct if not a replacement for other laboratory techniques which might be used for that purpose. 